Results one thousand three hundred twenty two indigenous participants were surveyed, sixty three \% were female, fifty five $55 \%$ less than thrirty five 35 years old. Syphilis prevalence was $9.7 \%$ (IC95\%: $8.2-11.5$ ) and that of HIV $0.4 \%$ (IC95\%: $0.40-1.0$ ). There was a difference between those diagnosed with HIV $<25$ years old: $0.6 \%$ (IC $0.5-1.2$ ) and $>25$ years old: $0.3 \%$ (IC $0.3-0.8$ ). Differences in syphilis prevalence among men (10.1\%) and women $(9.7 \%)$ weren't significant $(p=0.83)$. Seventy five $75 \%$ of the population initiated sexual relations < fifteen 15 years old. Condom use was $5.9 \%$.twenty one $21.2 \%$ reported having more than two sexual partners in the past year; in indigenous population $<25$ twenty five years old: $6.3 \%$ and $>25$ years old: $7.2 \%$ identified correctly the ways of preventing HIV infection and rejected erroneous ideas on the transmission of the virus.

Conclusions Syphilis prevalence is higher in natives than that of the general population of Paraguay; however, the HIV prevalence is similar. The low percentage of use of condom and knowledge of the syphilis and HIVare related factors that indicate the need of an urgent intervention from the national authorities to break the chain of transmission of STI in this population.

\section{P3.180 KNOWLEDGE ATTITUDE PRACTISES ABOUT SEXUALLY TRANSMITTED DISEASE AMONG THE COMMERCIAL SEX WORKERS}

doi:10.1136/sextrans-2013-051184.0637

${ }^{1} \mathbf{M}$ Karim, ${ }^{2} \mathrm{~N}$ Mona. 'National Institute of Preventive and Social Medicine (NIPSOM), Dhaka, Bangladesh; ${ }^{2}$ Bangladesh Medical college, Dhaka, Bangladesh

Objective To assess the knowledge, attitude and practises regarding STDs/RTI among the commercial sex workers.

Material and Methods It was a cross sectional study conducted among 204 commercial sex workers, residing in different places of Dhaka metropolitan city. Data were collected by questionnaire.

Results It was found that the mean age of commercial sex workers was 17.8 years. Regarding educational status, 57\% of the respondents were illiterate, $30 \%$ primary level and $13 \%$ were secondary level of education. It was found that $40 \%$ of the respondents were unmarried followed by $50 \%$ abandoned. Majority of the respondents $93 \%$ heard about STDs/RTI, but knowledge regarding STDs/RTI among the respondents was not adequate. Majority of the respondents $74 \%$ had fair knowledge followed by poor knowledge $17 \%$. Only $19 \%$ of the respondents had good knowledge. Regarding attitude, more than half of the respondents $57 \%$ agreed that STDs/RTI are harmful disease and need proper treatment followed by strongly agreed 3.6\%. About three fourth of the respondents $70 \%$ agreed that condom should be used during every sexual act followed by strongly agreed $23 \%$ and only $3 \%$ of the respondents disagreed. It was also found that $73 \%$ of the respondents needed more knowledge about STDs/RTI. Nature of the sexual practise among the commercial sex workers was per vaginal $94 \%$, only $6 \%$ of the respondents reported oral sex either forceful or taking high money.

Conclusion The magnitude of the problems of STDs/RTI is an increasing public health concern in Bangladesh. It was evident that preventive measures among them were inadequate. It was clear that most of the commercial sex workers having STDs did not seek medical treatment. Provision of appropriate health information with focus on health education improves their knowledge about STDs/ RTI with its symptoms, prevention and hygienic practise.

\section{P3.181 THE ASSOCIATION BETWEEN ALCOHOL USE AND SEXUALLY TRANSMITTED INFECTION(STI) INCIDENCE AMONG KENYAN WOMEN ENGAGED IN TRANSACTIONAL SEX}

doi:10.1136/sextrans-2013-051184.0638
K S Wilson, ${ }^{2} \mathrm{~K}$ Odem-Davis, ${ }^{3} \mathrm{~F}$ Kashonga, ${ }^{3} \mathrm{G}$ Wanje, ${ }^{3} \mathrm{~W}$ Jaoko, ${ }^{3} \mathrm{~B}$ Estambale, ${ }^{1} \mathrm{R}$ McClelland. 'University of Washington, Seattle, WA, United States; ${ }^{2} F r e d$ Hutchinson

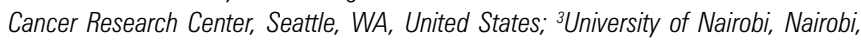
Kenya

Background Few prospective studies have examined the association between alcohol use and sexually transmitted infections (STI) among African women. We evaluated whether alcohol use was associated with increased risk of STI in a cohort of Kenyan women.

Methods We analysed data from a prospective study of women who report transactional sex in Mombasa. Women 18 and older who enrolled between 2006 and 2011 were included. Participants could contribute up to two years of follow-up. Baseline alcohol use was categorised as none, 1-7, or $\geq 8$ drinks/week. STIs (gonorrhoea, Chlamydia, and Trichomonas) and sexual risk behaviours were assessed monthly. The association between alcohol use and any STI was evaluated by logistic regression using generalised estimating equations.

Results Overall, 622 women contributed 368 person-years of observation. Of these, 161(25.8\%) were HIV-positive. Among HIVpositive women, 88 (54.7\%) reported 1-7 drinks/week and 31 $(19.3 \%)$ reported $\geq 8$ drinks/week. Among HIV-negative women, $248(53.8 \%)$ reported $1-7$ drinks/week and $100(21.7 \%)$ reported $\geq 8$ drinks/week. The association between alcohol use and STI risk was significantly different in HIV-positive compared to HIV-negative women $(p=0.05)$. Alcohol use was associated with STI acquisition only in HIV-positive women. Compared to non-drinkers, women who drank 1-7 drinks (odds ratio $[\mathrm{OR}]=2.3[1.0-5.5]$ ) and $\geq 8$ drinks/week $(\mathrm{OR}=3.2[1.0-10.6])$ had increased risk of STI. These associations were similar though no longer statistically significant after adjusting for age, workplace and marijuana use (1-7 drinks $\mathrm{OR}=2.3[1.0,5.3] ; \geq 8$ drinks $\mathrm{OR}=2.0[0.7,6.1]$ ).

Conclusion In this prospective analysis, baseline alcohol use was associated with an increased risk of STI among HIV-positive women. Addressing alcohol use problems in HIV care settings may offer additional benefits of reducing the burden of STIs among highrisk African women. Future research with time-varying measures of alcohol use will be important to further characterising the relationships between alcohol and STI risk in this population.

\section{P3.182 SEXUALLY TRANSMITTED INFECTION SCREENING AMONG HIV-NEGATIVE MEN AND WOMEN SEEKING HIV-TESTING ONLY: MISSED OPPORTUNITY FOR HIV PREVENTION?}

doi:10.1136/sextrans-2013-051184.0639

${ }^{1}$ R C Perkins, ${ }^{2} \mathrm{G}$ Douglass, ${ }^{2} \mathrm{~V} T a,{ }^{1} \mathrm{~A}$ Dright, ${ }^{2} \mathrm{M}$ Fomundam, ${ }^{3} \mathrm{Y} \mathrm{Li},{ }^{3} \mathrm{M}$ Plankey. ${ }^{1}$ WhitmanWalker Health, Washington, DC, United States; ${ }^{2}$ George Washington Unviersity School of Public Health, Washington, DC, United States; ${ }^{3}$ Georgetown University Medical Center, Department of Medicine Division of Infectious Diseases, Washington, DC, United States

Background Sexually transmitted infections (STIs) increase the risk of HIV infection; however concurrent HIV and STI testing may not be available in all clinical settings. In previous work, we showed a high concordance of self vs. provider STI testing. In this study, we evaluated the implementation of STI self-testing among HIV-negative, asymptomatic adults.

Methods Self collected urine, throat and/or rectal swabs for Chlamydia trachomatis (CT) and Neisseria gonorrhoeae (GC), without physical examination, were completed by 514 HIV-negative (rapid HIV test performed on same day), asymptomatic adults at a walkin clinic in Washington, DC. Sociodemographic and sexual risk behaviour data were collected, and a post-testing satisfaction survey was completed by each individual.

Results The sample included: $413(80.4 \%)$ men and 101(19.6\%) women. The median age was 30 (range 15-72) years. Among the men: 135 (32.7\%) African-American; 211 (51.1\%) White; 262 